\title{
Seasonal expressions of GPR41 and GPR43 in the colon of the wild ground squirrels (Spermophilus dauricus)
}

\author{
Xiaoying Yang, Xuhao Liu, Fengcheng Song, Hao Wei, Fuli Gao, Haolin Zhang, Yingying Han, Qiang Weng, \\ Zhengrong Yuan \\ College of Biological Sciences and Technology, Beijing Forestry University, Beijing, China
}

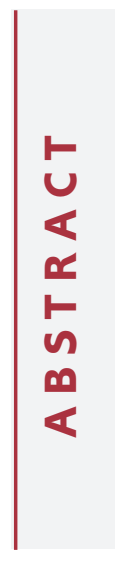

\begin{abstract}
G-protein-coupled receptor 41 (GPR41) and G-protein-coupled receptor 43 (GPR43) are important short-chain fatty acids (SCFAs) receptors. Previous studies indicated that GPR41 and GPR43 are involved in the secretion of gastrointestinal peptides, and glucose and lipid metabolism, and are closely related to obesity and type II diabetes, and other diseases. The purpose of the study was to explore the relationship of the GPR 41 and GPR43 with seasonal breeding, and provide new prospects for further exploring the nutritional needs of breeding. We identified the localization and expression levels of GPR41 and GPR43 in the colon of the wild ground squirrels (Spermophilus dauricus) both in the breeding season and non-breeding season. The histological results revealed that the lumen diameter of the colon had obvious seasonal changes, and the diameter of the colonic lumen in the non-breeding season was larger than that in the breeding season. Immunohistochemical staining suggested that GPR41 and GPR43 are expressed in the simple layer columnar epithelium. In addition, compared with the breeding season, the mRNA and protein expression levels of GPR41 and GPR43 in the colon were higher during the non-breeding season. In general, these results indicated that GPR41 and GPR43 might play a certain role in regulating seasonal breeding.
\end{abstract}

Key words: GPR41; GPR43; colon; wild ground squirrel; seasonal breeding.

Correspondence: Zhengrong Yuan, Laboratory of Animal Physiology, College of Biological Sciences and Biotechnology, Beijing Forestry University, Beijing 100083, China. E-mail: zryuan@bjfu.edu.cn

Contributions: XYY, XHL, FCS, HW, experiments performing, analysis and interpretation of data, drafting the article; FLG, HLZ, YYH, QW, ZRY, conception and design, supervision, final approval.

Conflict of interest: The authors declare that they have no competing interests.

Ethics approval: All procedures involving animals were carried out under the Policy on the Care and Use of Animals by the Ethical Committee, Beijing Forestry University and approved by the Department of Agriculture of Hebei Province, China (JNZF11/2007). 


\section{Introduction}

The colon, as a part of the large intestine, is a vital part of digestion and absorption. The large number of microbiota in the colon of mammals is similar to ruminants in quantity and species. The microbiota can produce short-chain fatty acids (SCFAs) from undigested carbohydrates. ${ }^{1}$ 95\% of SCFAs are produced and absorbed in the colon. ${ }^{2}$ SCFAs are mainly produced in the ascending colon and transverse colon (proximal colon), and the concentration of SCFAs can reach $70-140 \mathrm{mM}^{2}$ In the distal colon, SCFAs are rapidly absorbed by colonocytes, and only $5-10 \%$ of them are excreted through feces. ${ }^{3}$ SCFAs mainly include acetate $(\mathrm{C} 2)$, propionate $(\mathrm{C} 3)$, and butyrate $(\mathrm{C} 4)$ in the gut of humans and rodents, which are important anions in the colon that affect colon morphology, cell proliferation and differentiation, blood flow, and also have an important impact on the energy homeostasis and organism immune. ${ }^{4,5}$ Among them, acetate regulates lipid metabolism, maintains glucose homeostasis, and is important to maintain body weight and insulin sensitivity. ${ }^{6}$ Butyrate can also improve insulin sensitivity and increase energy consumption. ${ }^{7}$ Butyrate and propionate can regulate gut hormones level and maintain gut homeostasis. ${ }^{8}$ SCFAs can be utilized by colonocytes or enter the blood circulation in several different ways. One mechanism by which SCFAs regulate energy homeostasis is achieved by activating G-protein-coupled receptor 41 (GPR41) and G-protein-coupled receptor 43 (GPR43). ${ }^{9}$

G-protein-coupled receptors (GPCRs) are receptor proteins containing seven transmembrane regions. Free fatty acid receptor (FFAR) is the largest family of GPCRs, and its ligand is a free fatty acid (FFA).${ }^{10}$ According to the length of the carbon chain of FFAs, they are classified as LCFAs (long-chain fatty acids, more than 12 carbon atoms), MCFAs (medium-chain fatty acids, 7-12 carbon atoms), and SCFAs (1-6 carbons atoms). GPR41 (FFAR3) and GPR43 (FFAR2) are activated by SCFAs. ${ }^{11}$ Butyrate is more selective to GPR41, acetate is more selective to GPR43, and propionate binds to both receptors. ${ }^{12}$ However, the coupling situation differs between the two receptors with the G proteins. GPR41 mainly couples to $G_{i / o}$ which is sensitive to pertussis toxin, whereas GPR43 is dually coupled to $G_{\mathrm{i} / \mathrm{o}}$ and pertussis toxin insensitive $\mathrm{G}_{\mathrm{q} \cdot}{ }^{13}$ GPR43 is expressed by epithelial cells (ECs) in the large intestine, as well as in different tissues and cytoplasm including immune cells and adipose tissues. ${ }^{14-16}$ GPR41 is similarly expressed in ECs and adipose tissue, where it is also detected in sympathetic ganglia in mice and humans. ${ }^{17-19}$ Many studies have reported that GPR41 and GPR43 have crucial roles in regulating energy metabolism and immune response, but their effects on seasonal breeding have not been reported.

The wild ground squirrel (Spermophilus dauricus) is a lipidstoring hibernating animal, which has a long period of fattening before hibernation. ${ }^{20}$ The wild ground squirrel enters hibernation in October of each year, begins waking up in April of the following year, and subsequently enters the breeding season that lasts about one and a half months. So, April and May of each year are called the breeding season, the rest of the time is the non-breeding season..$^{21,22}$ In our previous work, we have indicated that seasonal breeding is dependent on hormonal regulation. P450 aromatase, androgen receptor, and estrogen receptor were differentially expressed in the testis, ${ }^{23}$ epididymis, ${ }^{24}$ and uterus ${ }^{25}$ between the breeding season and non-breeding season. At the same time, we also found that the number of gut microbiota that can decompose carbohydrates to produce SCFAs in the wild ground squirrel was different between the breeding season and the non-breeding season. ${ }^{26}$ This result allowed us to consider the regulatory effect of non-hormonal substances on seasonal breeding. As the receptors of SCFAs, the effects of GPR41 and GPR43 on seasonal breeding have not been fully studied. Thus, this study investigated the expression of GPR41 and GPR43 in the colon of the wild ground squirrels during the breeding season and non-breeding season, to clarify the role of SCFAs on seasonal breeding, and provide a theoretical basis for better exploring the conditions required for animal reproduction.

\section{Materials and Methods}

\section{Animals}

The wild ground squirrels were captured in April (breeding season, B) and June (non-breeding season, NB) in Hebei Province as experimental samples. All the procedures were complied with the policy on the Care and Use of Animals by the Ethical Committee, Beijing Forestry University, and approved by the Department of Agriculture of Hebei province, China (JNZF11/2007). The colon was quickly collected and the gut contents were rinsed out. Half of the clean colon samples were fixed with $4 \%$ paraformaldehyde (Sigma-Aldrich, St. Louis, MO, USA) for $24 \mathrm{~h}$, and stored in $70 \%$ alcohol, while the other half of the colon tissues were cut up and immediately put into liquid nitrogen and finally stored in $-80^{\circ} \mathrm{C}$ for mRNA and protein detections.

\section{Histology}

The colon samples stored in $70 \%$ alcohol were successively soaked in gradient alcohol for dehydration, followed by vitrification with dimethylbenzene and embedded in wax. The solidified wax block was cut into 5-7 $\mu \mathrm{m}$ serial sections for hematoxylineosin (HE) staining to observe tissue morphology.

\section{Immunohistochemistry}

After dewaxing, the sections were incubated with citric acid for antigen retrieval via autoclave for $10 \mathrm{~min}$ at $121^{\circ} \mathrm{C}$, followed by stringent treatment with $3 \%$ hydrogen peroxide for $30 \mathrm{~min}$. The sections were incubated with goat serum working fluid from the Histostain ${ }^{\mathrm{TM}}$-Plus Kits (SP-0022, Beijing Biosynthesis Biotechnology Co., Ltd., Beijing, China) for $30 \mathrm{~min}$. After that, the sections were incubated overnight under $4^{\circ} \mathrm{C}$ using primary polyclonal antibodies GPR41 (1:200 diluted in PBS, AF9075, Affinity Biosciences Ltd., OH, USA), GPR43 (1:200 diluted in PBS, bs13536R, Beijing Biosynthesis Biotechnology Co., Ltd., Beijing, China) and normal rabbit $\mathrm{IgG}$, respectively. Then, incubation was continued using a secondary antibody (goat anti-rabbit IgG conjugated with biotin from the Histostain ${ }^{\mathrm{TM}}$-Plus Kits), followed by using DAB (3,3'-diaminobenzidine) chromogenic agent (Wako, Tokyo, Japan) to visualize. Finally, the nucleus was stained with hematoxylin solution (Merck, Tokyo, Japan). Then the slides were observed under photomicroscope (BX51, Olympus, Tokyo, Japan) after being sealed. The colonic diameter of five wild ground squirrels in each season was measured by ImageView (x64, v. 3.7). For each sample, five fields were selected to analyze the positive expression.

\section{Total RNA isolation}

$0.1 \mathrm{~g}$ of colon tissues stored at $-80^{\circ} \mathrm{C}$ were homogenized with $1 \mathrm{~mL}$ Trizol reagent (Invitrogen, Carlsbad, CA, USA). After extensive lysis, $0.2 \mathrm{~mL}$ chloroform was added to it. Next, the mixture was mixed vigorously and was centrifuged at $4{ }^{\circ} \mathrm{C}$ after letting it keep for for 2-3 $\mathrm{min}$. The upper aqueous phase was carefully pipetted to a new tube and was added $0.8 \times$ volume isopropanol to keep for $10 \mathrm{~min}$. The solutions were centrifuged and the white precipitates which were total RNA of colon tissues were observed. The white RNA precipitates were washed with $75 \%$ cold ethanol. After 
the ethanol was volatilized, the white RNA precipitates turned transparent and dissolved in $40 \mu \mathrm{L}$ of diethylpyrocarbonate-treated water.

\section{Real-time quantitative PCR (qPCR)}

The cDNA fragment was synthesized by reverse transcription using the GoScript ${ }^{\mathrm{TM}}$ Reverse Transcription System (Promega Corporation, Madison, WI, USA) based on the manufacture's protocol. qPCR was tested using the ABI Prism 7500 Fast Real-Time PCR System (Applied Biosystems, Foster City, CA, USA). The reaction system of each volume was as follows: $1 \mu \mathrm{g}$ cDNA fragment, $0.1 \mu \mathrm{L}$ forward and reverse primers (sequences were listed in Table 1), $5 \mu$ L Hieff UNICON $1^{\mathbb{R}}$ Universal Blue qPCR SYBR Green Master Mix (Yeasen Biotech Co., Ltd., Shanghai, China), and sterile ultrapure water was brought up to total $10 \mu \mathrm{L}$. $\beta$-actin gene was used as an internal standard.

\section{Western blotting}

$0.1 \mathrm{~g}$ of chopped colon tissues were made into tissue homogenates. After fully cracking, the supernatant was extracted by centrifugation at $12,000 \mathrm{~g}$ at $4^{\circ} \mathrm{C}$ for $6 \mathrm{~min}$, which was the total protein in the tissues. $40 \mu \mathrm{g}$ extracted protein was mixed $3: 1$ with $4 \mathrm{X}$ SDS-PAGE Sample Loading Buffer, denatured by boiling for $5 \mathrm{~min}$ and run on a $12 \%$ SDS-polyacrylamide gels (SDS-PAGE) at 18 $\mathrm{V} / \mathrm{cm}$, then transferred to PVDF membranes. The membranes were blocked in 5\% non-fat milk for $1 \mathrm{~h}$ and incubated overnight in the primary antibodies of GPR41 (rabbit polyclonal, 1:800 dilution) and GPR43 (rabbit polyclonal, 1:800 dilution). Mouse polyclonal anti- $\beta$ actin (1:1000 dilution) (AM1021B, Abgent Biotechnology, Suzhou, China) was used as the control. Membranes were continued by incubation with the appropriate secondary antibodies (goat anti-rabbit IgG for GPR41 and GPR43, goat anti-mouse IgG for $\beta$-actin) linked to horseradish peroxidase for $1 \mathrm{~h}$. Finally, DAB was used for visualizing the binding of the antibody.

\section{Statistical analysis}

Comparisons of the quantitative data between two groups were performed by Student's $t$-test using GraphPad Prism 7.0 (GraphPad Software Inc., CA, USA). Statistical values of $p<0.05$ were considered significant.

\section{Results}

\section{Seasonal changes in colon histology}

The dyeing results of the colonic histology in the wild ground squirrels during the breeding and non-breeding seasons were shown in Figure 1. We detected a significant difference in colonic diameter between the two seasons $(\mathrm{p}<0.05)$. The diameter of the

Table 1. Sequence of primers used for real-time quantitative PCR.

\begin{tabular}{llc} 
Gene name & Sequence of primer & Product size (bp) \\
GPR41 & F: 5'-AGCAGCGTCTTCTTCCTCAC-3' & 276 \\
& R:5'-ATAGCACAGGCCGATGATGG-3' & 266 \\
GPR43 & F: 5'ACTTGCTGTTGTTGCTGCTG-3' & \\
\hline R-actin & R'-GATGGTGCATGGCCAAAGG-3' & 223 \\
& F: 5'-GACTCGTCGTACTCCTGCTT-3' \\
\hline
\end{tabular}

GPR41, G-protein coupled receptor 41; GPR43, G-protein coupled receptor 43.
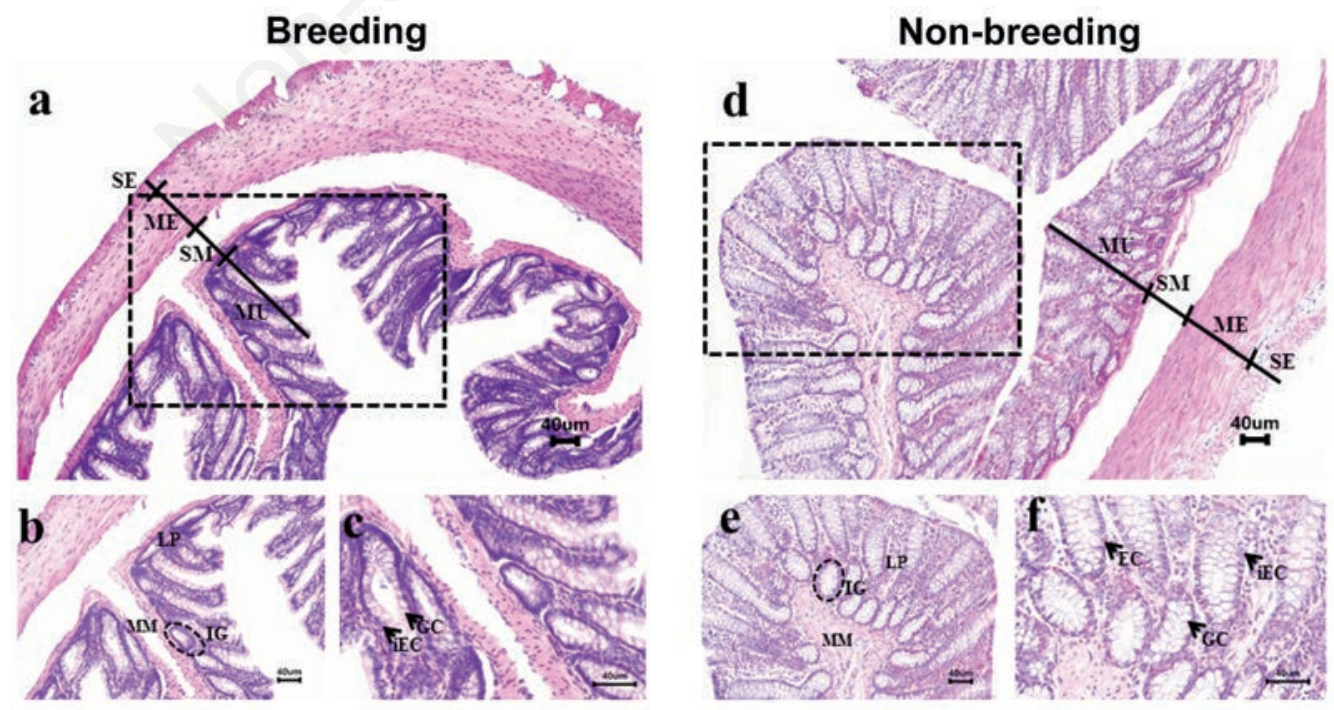

Figure 1. Histological features of the colon of the wild ground squirrels between the breeding season (a,b,c) and the non-breeding season (d,e f); $b$ and $e$ are the enlarged views of the dotted line of $a$ and $d$, respectively; $c$ and $f$ is the further enlarged view of $b$ and $e$, respectively. EC, enteroendocrine cells; GC, goblet cell; iEC, intestinal epithelial cells; IG, intestinal gland; LP, lamina propria; ME, muscularis externa; MM, muscularis mucosa; MU, mucosa. SE, serosa; $\mathrm{SM}$, submucosa. 
colon was significantly reduced during the breeding season $(\mathrm{p}<0.05$, Table 2$)$. In the mucosa, intestinal epithelial cells (iECs) and goblet cells (GCs) form intestinal glands. As shown in Figure $1 \mathrm{a}, \mathrm{b}$ the mucosa thickened and the number of intestinal glands was increased during the non-breeding season.

\section{Immunochemical localization of GPR41 and GPR43 in the colon}

Immunochemical staining of GPR41 and GPR43 in the colon during the two seasons was shown in Figure 2. GPR41 was located in the simple layer columnar epithelium which is composed of iECs and GCs in both two seasons (Figure 2 a,d). The same as the localized expression of GPR41, GPR43 was also present in the simple layer columnar epithelium (Figure 2 b,e).

\section{The expressions of GPR41 and GPR43 in the colon}

Seasonal expression of GPR41 and GPR43 mRNA levels in the colon was detected (Figure 3 ). Using $\beta$-actin as an internal control, both GPR41 and GPR43 mRNA expressions were significantly higher in the non-breeding season than in the breeding season $(\mathrm{p}<0.05)$. The protein expression levels have the same pattern as the mRNA expression levels. GPR41 and GPR43 protein levels markedly dropped in the breeding season (Figure 4).

\section{Discussion}

This study revealed that the seasonal expression patterns of SCFAs receptors, GPR41 and GPR43, in the colon of the wild ground squirrels during the breeding and non-breeding seasons. The results showed the expression patterns of GPR41 and GPR43 in the colon varied with the seasonal breeding changes. The immunohistochemical results indicated that both GPR41 and GPR43 were located in the simple layer columnar epithelium. The localization of GPR41 and GPR43 were consistent with the results in other rodents and humans. ${ }^{14,27,28}$ In the mice colon, GPR43 is detected mainly in the superficial portion of the crypt glands. ${ }^{27}$ In the rat colon, immunoreactivity of GPR43 is localized in enteroen-

Table 2. Diameter of colon during the breeding and non-breeding seasons.

Period Diameter of colon ( $\mathrm{mm}$ )

Breeding season $2.27 \pm 0.23^{* * *}$

Non-breeding season $\quad 3.30 \pm 0.11$

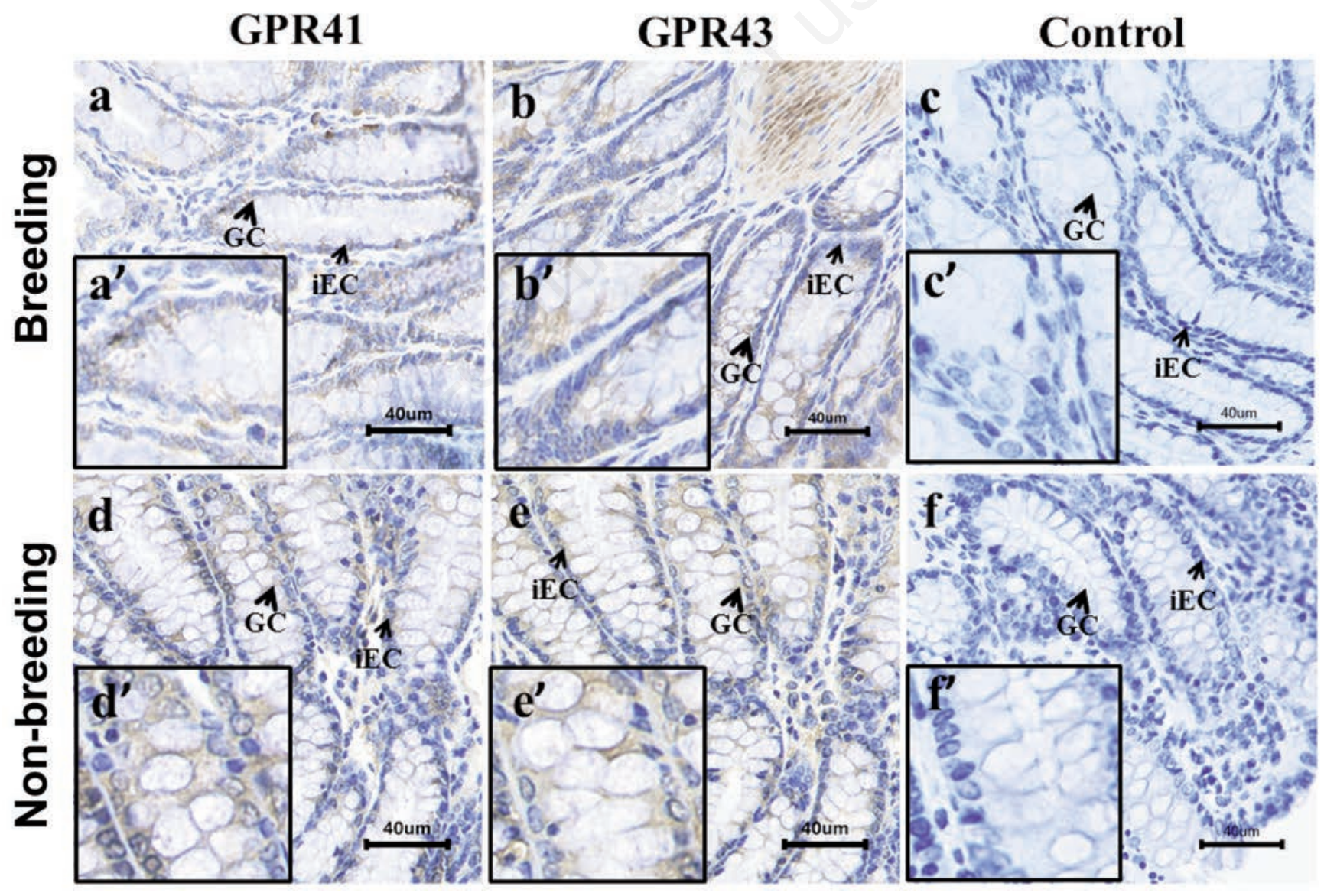

Figure 2. Immunohistochemistry of GPR41 and GPR43 in the colon of the wild ground squirrels between the breeding and non-breeding seasons. a) Immunolocalization of the GPR41 in the breeding season. b) Immunolocalization of the GPR43 in the breeding season. c) Negative control of the breeding season. d) Immunolocalization of the GPR41 in the non-breeding season. e) Immunolocalization of the GPR43 in the non-breeding season. f) Negative control of the non-breeding season. B, breeding season; NB, non-breeding season; GC, goblet cell; iEC, intestinal epithelial cells. 
docrine cells and the columnar epithelium of the mucosa of the distal colon. ${ }^{28}$ In immunohistochemical staining for GPR43 in the human colon, GPR43 immunoreactivity can be observed as dot staining in the cytoplasm of almost all iECs and many lamina propria cells. Moreover, the GPR43 antibody shows stronger staining in the surface epithelium relative to the crypt bottom. ${ }^{14}$ GPR41 is similarly localized in the cytoplasm of iECs and intestinal enteroendocrine cells in human colonic mucosa. ${ }^{29}$ Intestinal endocrine cells are a small part of intestinal epithelial cells, which can release a variety of hormones and neurotransmitters to regulate physiological responses. Several studies have shown that GPR41 and GPR43 are expressed by enteroendocrine L cells that secrete peptide YY (PYY) and glucagon-like peptide-1 (GLP-1) and participate in energy metabolism. Both GPR41 and GPR43 colocalize with PYY in colonic enteroendocrine $\mathrm{L}$ cells, ${ }^{28,29}$ and GPR43 immunoreactivity colocalizes almost completely with GLP-1. ${ }^{30} \mathrm{~L}$ cells are part of the endocrine system of the intestine and are diffusely distributed in the intestinal epithelium, in which round granules are evenly distributed. L cells have a certain number in the colon, and their apical surface is constantly deep in the gut lumen and responds directly to signals in the gut lumen. ${ }^{31}$ Samuel et al. raised GPR41 gene knockout mice and wild-type mice under normal intestinal microbial conditions and sterile conditions respectively. Studies have shown that the level of PYY in the GPR41

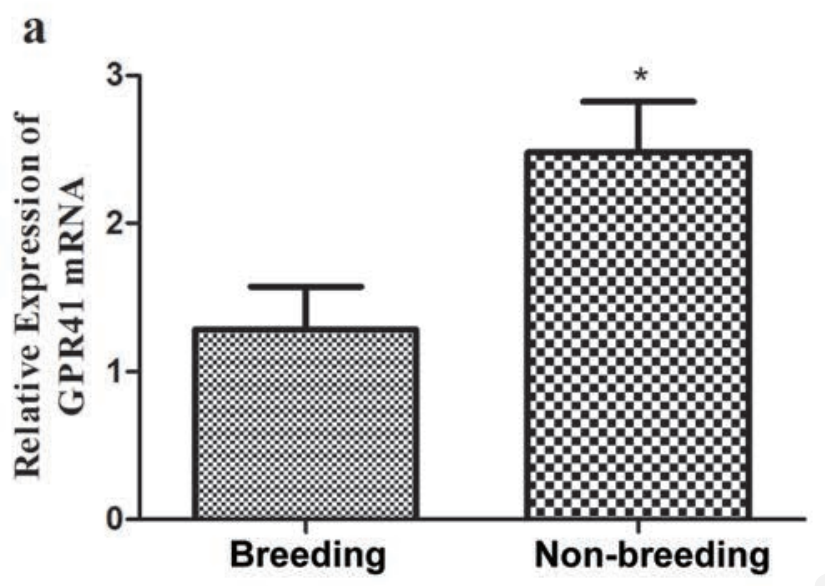

b

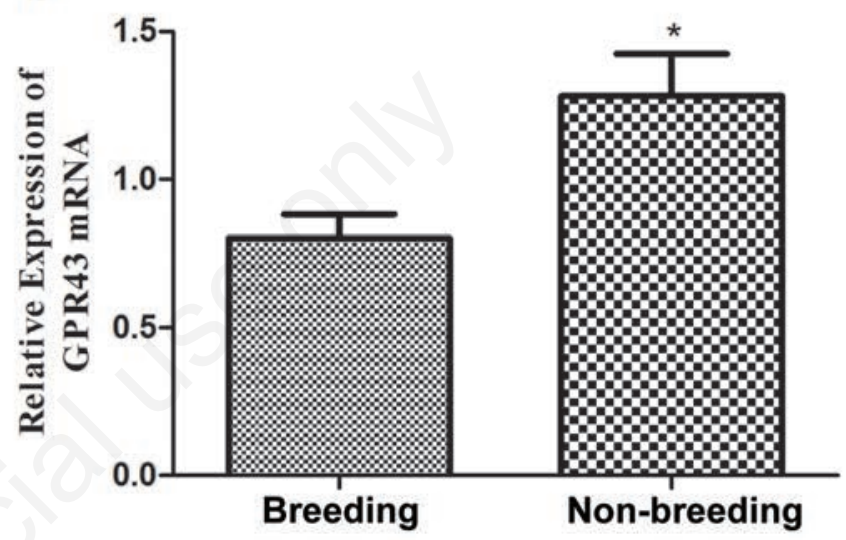

Figure 3. mRNA expression levels of GPR41 (a) and GPR43 (b) during the breeding and non-breeding seasons. Three individuals per season were tested for real-time quantitative PCR. Marked above bars indicate significant differences in gene expression between the two seasons. Data were shown as the mean \pm SEM; ${ }^{*} \mathrm{p}<0.05$. SEM, standard error of the mean.
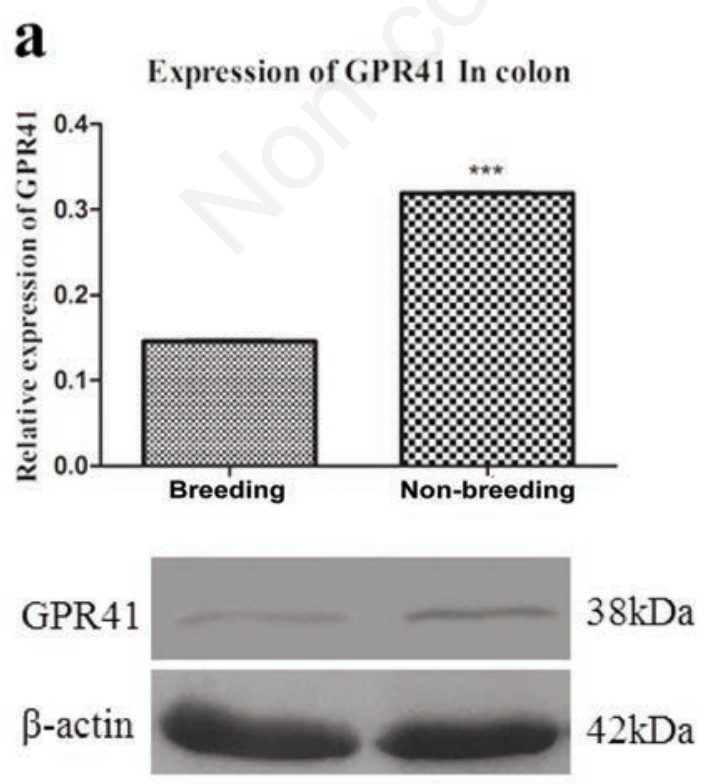

b
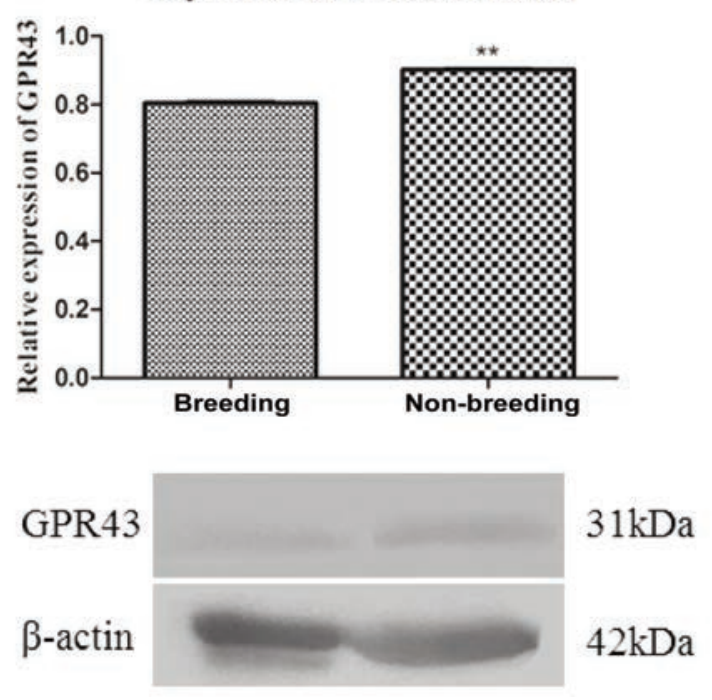

Figure 4. Protein expression levels of GPR41 (a) and GPR43 (b) during the breeding and non-breeding seasons. Three individuals per season were tested for Western blotting. $\beta$-actin blots were used as an internal control. Data were shown as the mean \pm SEM; ${ }^{* *} \mathrm{p}<0.01$; ${ }^{* * *} \mathrm{p}<0.001$. SEM, standard error of the mean. 
knockout mice is reduced, which increases the intestinal transport rate and reduces the efficiency of obtaining energy from the diet. ${ }^{32}$ Overall, in iECs SCFAs, as a signal molecule, bind and activate GPR41 and GPR43 to induce the release of PYY and GLP-1.

The qPCR and Western blotting were also used to explore the expression levels of GPR41 and GPR43 in the colon of the wild ground squirrels at the mRNA level and protein level, respectively. Significantly higher expression levels of GPR41 and GPR43 in the colon were found in the non-breeding season when compared to those in the breeding season, and the results of mRNA and protein levels were consistent. These results suggested that SCFAs had a certain regulatory effect on seasonal breeding by acting on GPR41 and GPR43. Recently, several studies have shown that GPR41 and GPR43 have important roles in improving body energy metabolism and regulating immune responses. GPR41 does not directly regulate fat degradation or synthesis but is associated with leptin synthesis in adipocytes. Xiong et al. overexpressed GPR41 cDNA and interfered with GPR41 mRNA expression in the Ob-Luc cell line respectively, and after stimulation with propionate, leptin gene expression levels were also increased and decreased respectively. They also found that treatment with $\mathrm{G}_{\mathrm{i} / \mathrm{o}}$ protein inhibitor pertussis toxin completely abolished the stimulatory effect of propionate on leptin production in Ob-Luc cells and mouse adipose tissue in culture, indicating that GPR41 is expressed in adipose tissue, and SCFAs can stimulate leptin secretion by activating the $\mathrm{G}_{\mathrm{i} / \mathrm{o}}$ pathway. ${ }^{18}$ Hong et al. showed that GPR43, rather than GPR41, was highly expressed in the adipose tissue of the mouse. The mRNA expressions of GPR43 and leptin in the fat of mice fed a high-fat diet were up-regulated compared with those of mice fed a normal diet, indicating that GPR43 plays a certain role in the fat accumulation pathway. At the same time, acetate and propionate can stimulate GPR43 in differentiated adipocytes and induce fat accumulation, suggesting the function of GPR43 and its ligands as regulators of adipogenesis. ${ }^{16}$ Zaibi et al. also reported that GPR43 can mediate leptin responses. ${ }^{33}$ In this study, GPR41 and GPR43 expression levels were increased in the colon during the nonbreeding season. As a lipid storing hibernating animal, the wild ground squirrels begin to prepare for hibernation after the breeding season. During this period, animals nearly double their body weight and increase white adipose due to overfeeding. They rely on reserve adipose to provide energy for their own needs during hibernation. ${ }^{34}$ The present study further supported the view that SCFAs modulate energy metabolism by activating GPR41 and GPR43 to affect seasonal breeding.

Insulin is the only glucose-lowering hormone in the body while promoting glycogen, fat, and protein synthesis. One of the causes of type II diabetes is that the pancreatic $\beta$ cells are unable to release sufficient amounts of insulin to balance blood glucose. Available reports indicated that GPR41 and GPR43 were expressed in pancreatic $\beta$ cells of mice and humans, and can inhibit insulin secretion via the $\mathrm{G}_{\mathrm{i} / \mathrm{o}}$ pathway. ${ }^{35}$ Veprik et al. showed that insulin secretion decreased in GPR41 overexpression mice, while GPR41 knockout mice showed hypoglycemic symptoms. ${ }^{36}$ Kimura et al. reported that GPR43 suppressed insulin signaling in adipose tissue and promoted the metabolism of glucose and lipids in other tissues to accelerate lipolysis. ${ }^{37}$ Glucose is the main energy supply material of organisms and the energy source of cells. However, in the early stage of mammalian embryonic development, it is not dependent on glucose. ${ }^{38}$ Even in the experiment of sheep embryo culture in vitro, it showed that the presence of glucose was harmful to the embryo. ${ }^{39}$ In this study, the expression of GPR41 and GPR43 decreased in the breeding season, which was speculated to promote the secretion of insulin and inhibit glucose and lipid metabolism, thereby providing sufficient energy protection for breeding.
In summary, the study demonstrated the localization and expression patterns of GPR41 and GPR43 in the colon of the wild ground squirrels during the breeding and non-breeding seasons. The results showed that GPR41 and GPR43, as the main receptors of SCFAs, were differentially expressed during the breeding and non-breeding seasons. The present study primarily explored the potential effects of GPR41 and GPR43 on the seasonal breeding.

\section{Acknowledgments}

This research work is supported by the National Natural Science Foundation of China (21806010), Fundamental Research Funds for the Central Universities (2018ZY21), and the National Training Program of Innovation and Entrepreneurship for Undergraduates (G202110022020, S202010022079, G202010022072).

\section{References}

1. Savage DC. Gastrointestinal microflora in mammalian nutrition. Annu Rev Nutr 1986;6:155-78.

2. Topping DL, Clifton PM. Short-chain fatty acids and human colonic function: roles of resistant starch and nonstarch polysaccharides. Physiol Rev 2001;81:1031-64.

3. Boets E, Deroover L, Houben E, Vermeulen K, Gomand SV, Delcour JA, et al. Quantification of in vivo colonic short chain fatty acid production from insulin. Nutrients 2015;7:8916-29.

4. Scheppach W. Effects of short chain fatty acids on gut morphology and function. Gut 1994;35:S35-8.

5. Macia L, Thorburn AN, Binge LC, Marino E, Rogers KE, Maslowski KM, et al. Microbial influences on epithelial integrity and immune function as a basis for inflammatory diseases. Immunol Rev 2012;245:164-76.

6. Hernández MAG, Canfora EE, Jocken JWE, Blaak EE. The short-chain fatty acid acetate in body weight control and insulin sensitivity. Nutrients 2019;11:1943.

7. Gao Z, Yin J, Zhang J, Ward RE, Martin RJ, Lefevre R, et al. Butyrate improves insulin sensitivity and increases energy expenditure in mice. Diabetes 2009;58:1509-17.

8. Lin HV, Frassetto A, Jr EJK, Nawrocki AR, Lu MM, Kosinski $\mathrm{JR}$, et al. Butyrate and propionate protect against diet-induced obesity and regulate gut hormones via free fatty acid receptor 3-independent mechanisms. PLoS One 2012; 7:e35240.

9. Brown AJ, Goldsworthy SM, Barnes AA, Eilert MM, Tcheang L, Daniels D, et al. The Orphan G protein-coupled receptors GPR41 and GPR43 are activated by propionate and other short chain carboxylic acids. J Biol Chem 2003;278:11312-19.

10. Pan P, Oshima K, Huang Y-W, Agle KA, Drobyski WR, Chen $\mathrm{X}$, et al. Loss of FFAR2 promotes colon cancer by epigenetic dysregulation of inflammation suppressors. Int $\mathrm{J}$ Cancer 2018;143:886-96.

11. Kimura I, Ichimura A, Ohue-Kitano R, Igarashi M. Free fatty acid receptors in health and disease. Physiol Rev 2020;100:171-210.

12. Haraa T, Kashiharaa D, Ichimurac A, Kimuraa I, Tsujimotoa G, Hirasawa A. Role of free fatty acid receptors in the regulation of energy metabolism. Biochim Biophys Acta 2014;1841:1292-300

13. Le Poul E, Loison C, Struyf S, Springael J-Y, Lannoy V, Decobecq ME, et al. Functional characterization of human receptors for short chain fatty acids and their role in polymorphonuclear cell activation. J Biol Chem 2003;278:25481-9. 
14. Karaki S-i, Tazoe H, Hayashi H, Kashiwabara H, Tooyama K, Suzuki Y, et al. Expression of the short-chain fatty acid receptor, GPR43, in the human colon. J Mol Histol 2008;39:135-42.

15. Venegas DP, Fuente MKD1, Landskron G, González MJ, Quera R, Dijkstra G, et al. Short chain fatty acids (SCFAs)-mediated gut epithelial and immune regulation and its relevance for inflammatory bowel diseases. Front Immunol 2019;10:277.

16. Hong Y-H, Nishimura Y, Hishikawa D, Tsuzuki H, Miyahara $\mathrm{H}$, Gotoh $\mathrm{C}$, et al. Acetate and propionate short chain fatty acids stimulate adipogenesis via GPCR43. Endocrinology 2005;146:5092-99.

17. Tolhurst G, Heffron H, Lam YS, Parker HE, Habib AM, Diakogiannaki E, et al. Short-chain fatty acids stimulate glucagon-like peptide-1 secretion via the G-protein-coupled receptor FFAR2. Diabetes 2012;61:364-71.

18. Xiong Y, Miyamoto N, Shibata K, Valasek MA, Motoike T, Kedzierski RM, et al. Short-chain fatty acids stimulate leptin production in adipocytes through the $\mathrm{G}$ protein-coupled receptor GPR41. Proc Natl Acad Sci USA 2004;101:1045-50.

19. Kimuraa I, Inouea D, Maedaa T, Hara T, Ichimura A, Miyauchi $\mathrm{S}$, et al. Short-chain fatty acids and ketones directly regulate sympathetic nervous system via G protein-coupled receptor 41 (GPR41). Proc Natl Acad Sci USA 2011;108:8030-5.

20. Song Y, Yang X, Zhang X, Zhu J, Chen Y, et al. Seasonal expression of extracellular signal regulated kinases in the colon of wild ground squirrels (Spermophilus dauricus). Res Square 2021. Available from: https://www.research square.com/article/rs-841280/v1

21. Yu W, Zhang Z, Liu P, Yang Y, Zhang H, Yuan Z, et al. Seasonal expressions of SPAG11A and androgen receptor in the epididymis of the wild ground squirrels (Citellus dauricus Brandt). Eur J Histochem 2020;64:3111.

22. Yuan Z, Wang Y, Yu W, Xie W, Zhang Z, Wang J, et al. Seasonal expressions of oxytocin and oxytocin receptor in the epididymides in the wild ground squirrels (Citellus Dauricus Brandt). Gen Comp Endocrinol 2020;289:113391.

23. Li Q, Zhang F, Zhang S, Sheng X, Han X, Weng Q, et al. Seasonal expression of androgen receptor, aromatase, and estrogen receptor alpha and beta in the testis of the wild ground squirrel (Citellus dauricus Brandt). Eur J Histochem 2015;59:2456.

24. Wang J, Liu Q, Qi H, Wang Y, Gao Q, Gao F, et al. Seasonal expressions of androgen receptor, P450arom and estrogen receptors in the epididymis of the wild ground squirrel (Citellus dauricus Brandt). Gen Comp Endocrinol 2019;270:131-38.

25. Wang Y, Wang Z, Yu W, Sheng X, Zhang H, Han Y, et al. Seasonal expressions of androgen receptor, estrogen receptors and cytochrome P450 aromatase in the uteri of the wild Daurian ground squirrels (Spermophilus dauricus). Eur J Histochem 2018;62:2889.

26. Yang X, Yao Y, Zhang X, Zhong J, Gao F, et al. Seasonal changes in the distinct taxonomy and function of the gut microbiota in the wild ground squirrel (Spermophilus dauri- cus). Animals 2021;11:2685.

27. Chang SC, Shen MH, Liu CY, Pu CM, Hu JM, Huang CJ. A gut butyrate-producing bacterium Butyricicoccus pullicaecorum regulates short-chain fatty acid transporter and receptor to reduce the progression of 1,2-dimethylhydrazine-associated colorectal cancer. Oncol Lett.2020;20:327-36.

28. Karaki S, Mitsui R, Hayashi H, Kato I, Sugiya H, Iwanaga T, et al. Short-chain fatty acid receptor, GPR43, is expressed by enteroendocrine cells and mucosal mast cells in rat intestine. Cell Tissue Res 2006;324:353-60.

29. Tazoe H, Otomo Y, Karaki S-I, Kato I, Fukami Y, Terasaki M, et al. Expression of short-chain fatty acid receptor GPR41 in the human colon. Biomed Res 2009;30:149-56.

30. Kaji I, Karaki S-i, Tanaka R, Kuwahara A. Density distribution of free fatty acid receptor 2 (FFA2)-expressing and GLP-1producing enteroendocrine $\mathrm{L}$ cells in human and rat lower intestine, and increased cell numbers after ingestion of fructooligosaccharide. J Mol Histol 2011;42:27-38.

31. Buffa R, Capella C, Fontana P, Usellini L, Solcia E. Types of endocrine cells in the human colon and rectum. Cell Tissue Res 1978; 192:227-40

32. Samuel BS, Shaito A, Motoike T, Rey FE, Backhed F, Manchester JK, et al. Effects of the gut microbiota on host adiposity are modulated by the short-chain fatty-acid binding $G$ protein-coupled receptor, Gpr41. Proc Natl Acad Sci USA 2008; 105:16767-72.

33. Zaibi MS, Stocker CJ, O'Dowd J, Davies A, Bellahcene M, Cawthorne MA, et al. Roles of GPR41 and GPR43 in leptin secretory responses of murine adipocytes to short chain fatty acids. FEBS Lett 2010;584:2381-6.

34. Giroud S, Habold C, Nespolo RF, Mejías C, Terrien J, Logan $\mathrm{SM}$, et al. The torpid state: Recent advances in metabolic adaptations and protective mechanisms (dagger). Front Physiol 2020;11:623665.

35. Tang C, Ahmed K, Gille A, Lu S, Gröne HJ, Tunaru S, et al. Loss of FFA2 and FFA3 increases insulin secretion and improves glucose tolerance in type 2 diabetes. Nat Med 2015;21:173-7.

36. Veprik A, Laufer D, Weiss S, Rubins N, Walker MD. GPR41 modulates insulin secretion and gene expression in pancreatic beta-cells and modifies metabolic homeostasis in fed and fasting states. FASEB J 2016;30:3860-9.

37. Kimura I, Ozawa K, Inoue D, Imamura T, Kimura K, Maeda T, et al. The gut microbiota suppresses insulin-mediated fat accumulation via the short-chain fatty acid receptor GPR43. Nat Commun 2013;4:1829.

38. Chi F, Sharpley MS, Nagaraj R, Roy SS, Banerjee U. Glycolysis-independent glucose metabolism distinguishes TE from ICM fate during mammalian embryogenesis. Dev Cell 2020;53:9-26-e24.

39. Thompson DJG, Simpson AC, Pugh PA, Tervit HR. Requirement for glucose during in vitro culture of sheep preimplantation embryos. Mol Reprod Dev 1992;31:253-7.

Received for publication: 23 October 2021. Accepted for publication: 2 January 2022.

This work is licensed under a Creative Commons Attribution-NonCommercial 4.0 International License (CC BY-NC 4.0).

CCopyright: the Author(s), 2022

Licensee PAGEPress, Italy

European Journal of Histochemistry 2022; 66:3351

doi:10.4081/ejh.2022.3351 